\title{
Traços de aprendizagem significativa em uma atividade experimental de espectroscopia empregando Realidade Aumentada
}

\author{
Wilson Vanucci Costa Lima - UFSM, wilsonvanuccicl@gmail.com \\ Felipe Becker Nunes - AFM, nunesfb@gmail.com \\ Fabrício Herpich - UFRGS, fabricio_herpich@ hotmail.com \\ Pedro Paulo Araújo Barbosa - UFSM, pedro.pab@ hotmail.com \\ Cesar de Oliveira Lobo - UFSM, cesarolobo@gmail.com
}

\begin{abstract}
Resumo. Este trabalho tem como objetivo investigar de que forma uma atividade experimental sobre emissão de radiação atômica utilizando Realidade Aumentada pode se tornar potencialmente significativa no ensino superior, utilizando como referencial teórico a teoria de aprendizagem significativa, de David Ausubel. Para a atividade, utilizou-se um aplicativo de Realidade Aumentada, chamado avatARUFRGS, que permite a observação do espectro de radiação visível do hélio e do hidrogênio. A pesquisa tem caráter qualitativo e quantitativo do tipo estudo de caso. Após a análise dos dados, pode-se perceber que grande parte dos estudantes demonstraram indícios de aprendizagem significativa, uma vez que ancoraram conhecimentos novos aprendidos a conhecimentos prévios já estabelecidos na estrutura cognitiva.

Palavras-chave: Espectroscopia; Realidade Aumentada; Ensino de física; Aprendizagem Significativa.

\section{Meaningful learning traits in an experimental spectroscopy activity employing Augmented Reality}

Abstract. This paper aims to investigate how an experimental activity on atomic radiation emission using Augmented Reality can become potentially significant in higher education, using David Ausubel's theory of meaningful learning as a theoretical framework. For the activity, an Augmented Reality application called avatARUFRGS was used, which allows the observation of the visible radiation spectrum of helium and hydrogen. The research has qualitative and quantitative character case study type. After analyzing the data, it can be seen that most of the students showed signs of significant learning, since they anchored new knowledge learned to previous knowledge already established in the cognitive structure.

Keywords: Spectroscopy; Augmented Reality; Physics teaching; Meaningful Learning.

\section{INTRODUÇÃO}

Com o desenvolvimento das Tecnologias de Informação e Comunicação (TIC), foram permitidas formas diversas de interação entre alunos e tecnologias, modificando a concepção de cursos ou programas de ensino e de seus materiais didáticos, redefinindo a atuação do aluno e do professor frente aos novos espaços interativos de comunicação digital no século XXI (Barbosa, 2012). Nesse contexto, as TIC se inserem na educação básica e superior como uma ferramenta capaz de interagir com o estudante, tornando-o protagonista do aprendizado, além de proporcionar uma experiência inovadora e atrativa ao aprendiz.

No ensino superior, de acordo com Trindade (2014), as TIC permitem melhorar e facilitar o acesso aos documentos e materiais de trabalho e estudo, estimular uma maior eficiência e produtividade nos trabalhos acadêmicos e contribuir para uma ação 
pedagógica mais eficiente por parte dos professores. Portanto, elas podem contribuir com a mudança das práticas de ensino, desenvolvendo competências essenciais no ensino superior, permitindo a emancipação do conhecimento dos aprendizes (Alves et al., 2012).

Então, propondo a utilização de TIC para o Ensino de Física no ensino superior, foi realizada uma atividade experimental com alunos do curso de Agronomia, para a disciplina de física para ciências rurais. Essa atividade tem como objetivo explicar conceitos de espectro atômico e espectroscopia utilizando a radiação do espectro visível do hidrogênio e do hélio.

A atividade envolve o uso de um aplicativo de Realidade Aumentada (RA), chamado avatARUFRGS, desenvolvido através do Projeto AVATAR ${ }^{1}$, que possui diversos experimentos de física, aplicados a RA, encontrado em plataformas online de aplicativos, disponibilizado pela Universidade Federal do Rio Grande do Sul (UFRGS). A RA é um recurso tecnológico capaz de integrar elementos do mundo real com elementos do mundo virtual, utilizando a câmera como recurso principal, com o auxílio de sensores de movimento e giroscópio, sendo capazes de, por exemplo, mostrar o experimento presente neste trabalho em cima das mesas dos alunos, na sala de aula.

Para avaliar o aprendizado dos estudantes, foi entregue aos alunos um préquestionário, que visava avaliar os conhecimentos prévios deles e um pós-questionário, cujo objetivo era avaliar os conceitos e fenômenos aprendidos após a atividade. $\mathrm{O}$ referencial teórico utilizado para o trabalho é a teoria de aprendizagem de Ausubel (Ausubel, 1982). Para o autor, aprendizagem significativa é aquela em que a essência do novo conhecimento é incorporada a estrutura cognitiva do estudante, através de conhecimentos prévios, definidos por Ausubel como subsunçores. Através desses subsunçores, seremos capazes de mapear a estrutura cognitiva do aprendiz e definir a melhor maneira de apresentar a atividade proposta, analisando ao final se houveram indícios de aprendizagem significativa.

Após o pós-questionário, os alunos responderam um questionário do modelo MAREEA (Herpich et al., 2019) que tem como objetivo avaliar a motivação dos alunos na abordagem educacional de RA Móvel. Portanto, propomos entender o envolvimento dos alunos com o aplicativo, verificando se a aprendizagem foi o suficiente para mostrar aspectos do fenômeno que se relacionam com o cotidiano dos estudantes, além de verificar se a atividade facilitou o entendimento dos conceitos físicos discutidos no decorrer da aula. Se o aplicativo referente à RA facilitar a interação entre os conhecimentos prévios e os novos conhecimentos dos alunos, este material pode ser considerado potencialmente significativo.

Diante do que foi exposto, propomos responder o seguinte problema de pesquisa: De que forma a experimentação sobre espectro atômico, utilizando RA, pode contribuir para aprendizagem dos alunos no ensino superior?

Para ajudar a responder o problema, foram definidos dois objetivos, um geral e um específico. $\mathrm{O}$ objetivo geral é investigar de que forma uma atividade experimental sobre emissão de radiação atômica envolvendo RA pode se tornar potencialmente significativa, utilizando como referencial teórico a teoria de aprendizagem significativa. O objetivo específico do trabalho é implementar uma atividade experimental utilizando RA.

\section{REFERENCIAL TEÓRICO}

Nesta seção são abordados a definição e potencialidades de Realidade Aumentada e o referencial de aprendizagem significativa. 


\subsection{Realidade Aumentada}

A tecnologia pode ser definida como artefatos, métodos ou técnicas criadas pelo ser humano para tornar seu trabalho mais leve, sua locomoção e sua comunicação mais fáceis ou mesmo tornar sua vida mais divertida (Chaves, 1999). Nesse sentido, o uso de tecnologias no processo educacional pode facilitar na forma como o aluno interage com o conhecimento, tornando o processo de aprendizagem mais atrativo e menos superficial ao estudante.

Quando tratamos de tecnologia na educação, somos impelidos a entender a questão com uso de aparelhos computadorizados como ferramenta em ambientes educacionais. Essa correlação existe, pois, esses aparelhos possibilitam o uso de funcionalidades presentes em apenas um veículo tecnológico, a exemplo de aparelhos celulares, que são multifuncionais.

Desta forma, utilizando RA, adicionam-se informações e significados a um objeto real para aprofundar o entendimento e o conhecimento de um indivíduo em relação a um determinado assunto. Podemos derivar da definição de RA, três aspectos importantes para a interação com a tecnologia, descrita por Serio, Iaez e Kloos (2013): A RA permite a imersão, evolvendo os aspectos físicos do ambiente e a condição sob a qual o seu usuário está envolvido com as práticas propiciadas por essa tecnologia. Permite também a interação com o indivíduo, propiciando uma aprendizagem ativa, além da navegação, processo no qual os objetos reais e virtuais se alinham e a cada mudança de perspectiva do usuário da RA, o sistema será capaz de se adaptar a essa mudança. Este aspecto de navegação está diretamente ligado a imersão e a interação. A potencialidade da RA está no fato de ser permitido explorar ambientes, processos ou objetos que não seja através de livros, fotos ou aulas, mas analisando ou manipulando virtualmente o objeto de estudo.

A RA inserida no o ambiente educacional pode proporcionar um aprendizado mais dinâmico e atraente para os alunos. No ensino superior não é diferente, uma vez que a física se faz importante para o entendimento dos fenômenos naturais, provendo conceitos que serão úteis aos futuros profissionais.

\subsection{Aprendizagem significativa}

Para a referência teórica de aprendizagem, será utilizada a aprendizagem significativa, de David Ausubel, abordado por Moreira (2009). A aprendizagem significativa é aquela em que as ideias interagem de maneira substantiva e não arbitrária com o conhecimento prévio do aprendiz. Diz-se que é substantiva quando é não literal, ou seja, a essência do aprendizado é incorporada a estrutura cognitiva do estudante e não arbitrária significa que não pode ser qualquer ideia prévia a ser usada para a construção do conhecimento, mas sim conhecimentos especificamente relevantes.

Este conhecimento, que é relevante, chama subsunçor. Para Moreira, subsunçor é:

[...] o nome que se dá a um conhecimento específico, existente na estrutura do conhecimento do indivíduo, que permite dar significado a um novo conhecimento que lhe é apresentado ou por ele descoberto. Tanto por recepção como por descobrimento, a atribuição de significados a novos conhecimentos depende da existência de conhecimentos prévios especificamente relevantes e da interação com eles (2012, p. 2).

Ou seja, um subsunçor pode ser um conceito, uma imagem ou mesmo um modelo mental. 
De acordo com Moreira (2009), a organização das informações na mente humana forma uma hierarquia conceitual na estrutura cognitiva, no qual elementos mais específicos do conhecimento são assimilados a conceitos e proposições mais gerais. Essa organização decorre, em parte, da interação que caracteriza a aprendizagem significativa. Portanto, trata-se de um conhecimento dinâmico, não estático, que pode evoluir e, também, involuir.

Outro conceito importante proposto por Ausubel (1982) são os organizadores prévios. Quando o aprendiz não dispõe de subsunçores adequados que permitam atribuir significados a novos conhecimentos, usa-se o conceito de organizadores prévios. Podemos dividir esses organizadores em dois tipos, o expositivo e o comparativo. Usa-se o expositivo quando o material de aprendizagem não é familiar de nenhuma forma. A partir disso, então, cria-se uma ponte entre os termos familiares ao aprendiz e o novo conhecimento, para tornar o material potencialmente significativo, ou seja, que permitam a interação e subordinação dos novos conhecimentos a conhecimentos prévios. Quando o novo material é relativamente familiar, usa-se o organizador comparativo, que ajudará o estudante a integrar novos conhecimentos e discriminar esses conhecimentos de outros já existentes.

No entanto, de acordo com Moreira (2009), a aprendizagem mecânica é a que mais ocorre em disciplinas escolares, sendo caracterizada como uma aprendizagem sem significado, não requerendo grande compreensão, mas sim, a memorização. A aprendizagem, seja ela mecânica ou significativa, pode ocorrer de dois meios diferentes, de acordo com Ausubel (1982): Por recepção e por descoberta. O conhecimento por recepção ocorre quando o conhecimento é dado pronto ao aprendiz. A aprendizagem por descoberta se dá quando o indivíduo deve descobrir o novo conhecimento a ser adquirido. Se na etapa do descobrimento, o aluno interagir com a descoberta de forma ativa, pode indicar uma aprendizagem significativa, uma vez que permite o interesse do aluno na forma inovadora como o conhecimento que está sendo aprendido.

A partir dessas definições, utilizaremos a atividade experimental para averiguar de que forma os estudantes aprendem sobre o conteúdo de espectroscopia e radiação, analisando o potencial significativo do material e observando os indícios do tipo de aprendizado que os alunos obtiveram.

\section{METODOLOGIA}

A pesquisa é de caráter qualitativo descritiva, quantitativo e do tipo estudo de caso. Qualitativo descritiva pois será narrado o que acontece através de dados obtidos no contato direto entre o pesquisador com a situação a ser estudada, que retrata, prioritariamente, a perspectiva dos participantes envolvidos (Lüdke; André, 1986). Estudo de caso é definido como um estudo de um ou poucos objetos, de modo que permita um amplo e detalhado conhecimento, que possui as seguintes etapas: formulação do problema; definição da unidade-caso; determinação do número de casos; elaboração do protocolo; coleta de dados; avaliação e análise dos dados; preparação do relatório (Gil, 2002). Para a análise do fator motivação dos estudantes com a RA Móvel, foram analisados dados de forma quantitativa. Quantitativo, pois mostra a estatística das respostas objetivas dos alunos.

\subsection{Sujeitos da pesquisa}

Para a realização do trabalho, houve uma intervenção em uma turma, com 27 alunos, do curso de agronomia da Universidade Federal de Santa Maria, para a disciplina 
de Física para as Ciências Rurais. A intervenção ocorreu em duas aulas, com a primeira aula durando trinta minutos e a segunda aula durando uma hora.

\subsection{Instrumentos de coleta de dados}

Para a coleta de dados, foram realizadas anotações pelo bacharelando presente, registrando a fala dos estudantes no decorrer da implementação. Foi entregue aos alunos um pré-questionário antes da atividade experimental, composta por duas perguntas, um pós-questionário, após a intervenção, contendo duas perguntas e no final foi entregue um questionário para avaliar a motivação da abordagem educacional

Para analisar a aprendizagem dos alunos foram discutidas as anotações realizadas durante a implementação e o pré e pós questionário através das categorias definidas $a$ priori: Categoria A: respostas coerentes com a descrição do fenômeno físico; Categoria B: Respostas que não se aproximam da descrição do fenômeno físico e com o objetivo da atividade proposta.

No pré questionário, haviam as seguintes perguntas: 1.1 Como é possível conhecer moléculas e átomos presentes no sol, sendo que essa estrela está muito distante da terra? 1.2 Já ouviram falar dos átomos de hidrogênio $(H)$ e hélio $(\mathrm{He})$ ? Como você pode diferenciá-los?

No pós-questionário, foram apresentadas as seguintes perguntas: 2.1 Você observou o espectro do hidrogênio e do hélio. Quais suas diferenças? 2.2 Para identificar drogas ilegais, como cocaína $\left(\mathrm{C}_{17} \mathrm{H}_{21} \mathrm{NO}_{4} \mathrm{HCl}\right)$ e crack $\left(\mathrm{C}_{17} \mathrm{H}_{21} \mathrm{NO}_{4}\right)$, peritos criminais (geralmente servidores da polícia civil e federal) utilizam diferentes métodos. Como é possível diferenciar e identificar tais substâncias?

Essas questões foram utilizadas na intenção de identificar o conhecimento dos alunos com os fenômenos e conceitos físicos envolvidos. A partir de suas respostas, foi possível analisar se houveram indícios de aprendizagem significativa. Os questionários são baseados na implementação realizada no trabalho de Barbosa et al. (2019) que tinha como objetivo investigar e contribuir no processo de Ensino e Aprendizagem de Física considerando uma atividade experimental demonstrativa sobre emissão de radiação atômica, no Ensino Médio.

O questionário referente ao fator "Motivação" da abordagem educacional possui trinta e sete questões abordado pelo modelo MAREEA que tem como objetivo avaliar a percepção da qualidade em termos de experiência de uso e de aprendizagem dos seus usuários após a interação com tais recursos. Para o presente trabalho será discutido apenas os fatores de qualidade "Motivação" e suas respectivas dimensões apresentada e especificada por Herpich et al. (2019).

\subsection{Procedimento}

O experimento utilizado na implementação foi o de espectroscopia disponibilizado pelo aplicativo avatARUFRGS. Para acessar o aplicativo, os estudantes deveriam baixá-lo com acesso à Internet. Foi criado um código QR, disponibilizado em uma folha impressa (roteiro da atividade) que ao aproximar a câmera do código QR, o celular efetuava a leitura da imagem e executava o experimento de espectroscopia.

A intervenção ocorreu em dois momentos, separados em dois dias. No primeiro momento, ocorrido no primeiro dia, os estudantes responderam o pré-questionário. Essa primeira etapa é determinante para entender os conhecimentos prévios que possuem os alunos e mapear a melhor forma de ensinar os conceitos de espectroscopia. É importante lembrar que a aprendizagem significativa se caracteriza pela interação entre os 
conhecimentos a serem aprendidos pelos estudantes e ancorados com seus conhecimentos prévios.

\section{RESULTADOS E DISCUSSÃO}

No primeiro momento foram discutidos conceitos que seriam importantes para a atividade experimental, como radiação e espectro eletromagnético. Nesta parte, o professor destaca o conceito de radiação no espectro visível. Indagando os alunos, o educador então pergunta quais cores são possíveis de enxergar no espectro visível. Alguns alunos citaram os conceitos associados as cores vermelho, verde e roxo. Constata-se que alguns alunos já conheciam sobre espectro visível dos átomos e possuíam conhecimentos acerca de comprimento de onda e frequência. Esses conceitos prévios os ajudaram a entender o experimento proposto para a segunda aula. Após isso, o professor explica sobre as cores do espectro visível e como poderíamos vê-las através da dispersão da luz utilizando um prisma ou rede de difração.

No segundo momento da intervenção, foi realizada a seguinte problematização: Como poderíamos descobrir que tipos de elementos estavam presentes no Sol? Já fazendo referência à primeira pergunta contida no pré-questionário. Dois alunos responderam: "Pela análise da radiação que chega à terra". Outra aluna falou: "Através do telescópio". Outro aluno disse: "Por partículas que caem do sol".

Em seguida, foi indagado que tipo de radiação chega a terra. Um aluno respondeu que seria a infravermelha. Essa resposta mostra que o aluno possuía um subsunçor relacionado a radiação do infravermelho, que pode ser usado para contextualizar para radiações em gerais.

Depois desta primeira interação, foi explicado sobre a radiação emitida pelo sol e sobre o espectro contínuo, citando a lâmpada incandescente, que também emite uma radiação contínua. Utilizando os conhecimentos prévios dos alunos em relação à lâmpada incandescente e a radiação visível, pôde-se explicar um novo conceito, o de espectro contínuo, subordinando a nova ideia ao conceito da radiação emitida pela lâmpada. Então perguntamos se poderíamos enxergar esse espectro a olho nu. Os alunos responderam que não era possível. Então foi explicado sobre o fenômeno da difração de ondas e apresentado aos estudantes o modo que a luz se comportava ao interagir com uma rede de difração, podendo dessa forma, enxergar o espectro dos elementos através da luz incidida em um anteparo de análise espectral.

Neste momento, os estudantes abriram o aplicativo avatARUFRGS, e solicitou-se que observassem os diferentes elementos químicos presentes na simulação. Conforme os alunos foram interagindo com o aplicativo, foram familiarizando-se com a tecnologia e manejavam mais facilmente o experimento.

O primeiro espectro que enxergaram foi o espectro da lâmpada incandescente. Perguntou-se o que eles enxergavam ali. Um dos alunos falou: "Consigo ver várias cores, parecendo o arco-íris.”. Então, foi explicado que essas cores estão associadas a dispersão da radiação, remetendo ao conceito de espectro contínuo. Nota-se que os alunos, ao interagirem com experimento, estavam aprendendo por descoberta. Após isso, eles observaram o espectro do hidrogênio. Espontaneamente, os alunos iam dizendo as cores que enxergavam do espectro desse elemento. Um dos alunos citou: "Consigo enxergar vermelho, azul e roxo". Outra aluna perguntou se era possível enxergar radiação ultravioleta. Então, foi explicado, que a radiação que os seres humanos geralmente observam a olho nu é a da luz visível. Também foi pedido aos estudantes que comparassem o elemento sódio com o hélio e o hidrogênio. Um dos alunos disse: " $\mathrm{O}$ sódio parece mais amarelo". Uma outra aluna falou: "O sódio tem menos cor". Uma das 
alunas perguntou o porquê do sódio apresentar a cor amarela mais nítida. Foi então explicado que a maior parte do espectro visível de emissão do elemento está no amarelo.

Um dos alunos perguntou ao professor se não tem como um elemento ter um espectro muito parecido com outro e, por isso, ser confundido. O educador explica que existem espectros parecidos com outros, mas sempre há maneira para diferenciá-los através de espectros não presentes pela luz visível. Um aluno perguntou se aquele tipo de análise poderia ser feito em solos para diferenciar elementos. $\mathrm{O}$ professor responde afirmativamente, gerando um diálogo entre os alunos sobre as habilidades que são desenvolvidas durante o curso em relação a métodos utilizados em análise de solos. Percebe-se que o aluno conseguiu conectar o fenômeno físico a sua área de atuação, tornando a interdisciplinaridade presente. Neste momento, houve indicativo de uma aprendizagem significativa.

Percebe-se que o conhecimento a partir do descobrimento está associado ao fato dos alunos observarem o espectro e identificarem suas diferenças. Aliado a isso, o professor explica o conteúdo, tornando presente o aprendizado por recepção.

Após a realização da experimentação, os alunos responderam o pós-questionário e a avaliação deles em relação a RA, que serão discutidas a seguir.

Para avaliar o conhecimento adquirido e perceber se foi um aprendizado potencialmente significativo, analisamos o pós-questionário para compreender se os alunos conseguiam relacionar o experimento com as questões presentes, que estão ligados ao dia a dia dos alunos. É importante salientar que os conhecimentos prévios dos alunos possibilitaram a construção e o desenvolvimento de estruturas mentais que viabilizam o aprendizado eficaz.

Para analisar as respostas dos aprendizes, temos: Categoria A: Com os dados do pós-questionário, em relação a questão 2.1 , dezenove alunos escreveram que a diferença entre os elementos se fazia pelas cores presentes no espectro, como veremos por alguns relatos transcritos abaixo:

\begin{abstract}
Aluno 2: Os elementos emitem espectros de cores diferentes; Aluno 5: As cores, cada um possui um espectro de cores como se fosse um DNA; Aluno 6: Cada um emite um espectro luminoso diferente, a emissão muda de acordo com o elemento; Aluno 10: O espectro, ao emitirem radiação, pois o hélio eu observei o amarelo, azul, vermelho e roxo predominantemente. Já o hidrogênio, eu vi azul e vermelho, predominantemente;
\end{abstract}

Os estudantes não responderam o questionário de forma individualizada, tornando algumas respostas similares escritas no pós-questionário.

Para a questão 2.2, dezenove alunos conseguiram responder de forma satisfatória esta questão, como podemos ver em alguns trechos transcritos abaixo:

\footnotetext{
Aluno 3: Pelo espectro de cada elemento; Aluno 6: Cada elemento possui um espectro. Desta forma, poderia se diferenciar olhando o espectro; Aluno 10: Usando espectroscopia, uma vez que a cocaína apresenta o $\mathrm{HCl}$, daí pode-se analisar e ver se tem o espectro desse composto;
}

A partir dos resultados $70 \%$ dos alunos conseguiram associar o método de emissão de energia atômica com o método da espectroscopia. Portanto, os aprendizes relacionaram os conceitos aprendidos com uma situação do cotidiano. Ao compreender o fenômeno físico e relacionar com essa situação colocada pela questão, pode ser um indício de que houve a aprendizagem significativa.

Além disso, pode-se perceber que houve o envolvimento da maioria dos alunos com o experimento, contendo respostas que se aproximam da correta descrição do V. $17 \mathrm{~N}^{\mathrm{o}}$ 3, dezembro, 2019 RENOTE DOI: 
fenômeno físico. Esse envolvimento, ligado a descoberta aliada a aprendizagem por recepção, é um indicativo de que houve uma aprendizagem significativa.

Categoria B: Na questão 2.1, Cerca de oito alunos responderam incorretamente as questões propostas, confundindo conceitos físicos ou não condizendo as respostas com o proposto pela atividade experimental dada em sala de aula, como transcrito abaixo:

\begin{abstract}
Aluno 1: A diferença está no tamanho das ondas; Aluno 4: Além das cores, os elementos tinham diferentes velocidades ao se encontrarem com a luminosidade; Aluno 9: O hidrogênio é denso, representado por $\mathrm{H}_{2}$; Aluno 15: Diferença na intensidade da luz.
\end{abstract}

Oito alunos não conseguiram responder satisfatoriamente à questão 2.2, não relacionando os conhecimentos desenvolvidos na atividade com o questionamento da pergunta, como podemos perceber pelos trechos transcritos abaixo:

\begin{abstract}
Aluno 4: Pode-se fazer a análise química com sensores químicos; Aluno 9: Através de métodos químicos; Aluno 12: Pela densidade, massa ou cheiro; Aluno 13: Eles utilizam um papel no qual é fabricado para mudar de cor dependendo da sustância.
\end{abstract}

As respostas errôneas escritas por 30\% dos alunos podem se dar pela falha interação entre professor, aluno e experimento, uma vez que nem todos poderiam estar interessados em realizar as atividades. Nesse sentido, o professor deveria explorar formas de inserir esses estudantes desinteressados na problemática do experimento.

Podemos perceber que a maioria dos alunos ancoraram os conceitos novos em conhecimentos prévios, tornando assim, um aprendizado subordinado, pois a partir da questão dos elementos presentes do sol, os alunos relacionaram esse exemplo ao conhecimento de espectro e radiação atômica, percebendo regularidades em diferentes eventos que utilizam a mesma explicação física.

Após responderem o pós-questionário, os estudantes responderam outro questionário referente à interação com a RA Móvel, visando entender se esse processo experimental permite que a aula fique mais atrativa e com uma compreensão do fenômeno mais facilitada.

\title{
5.1 Sobre o questionário de motivação
}

Em relação ao fator de qualidade referente a motivação, foram avaliadas as dimensões de Atenção Focada, Relevância, Confiança e Satisfação. A respeito da dimensão que avaliou a percepção dos participantes, referente a Questão 16 (Q16), mais de 29,6\% dos alunos discordaram de que o aplicativo envolve seus usuários a ponto de perderem a noção do tempo, assim como mais de 55,6\% indicaram que o aplicativo não atraiu a ponto de permitir ignorar as coisas no entorno dos usuários (Q17). Entretanto, mais de 59,3\% dos avaliadores afirmaram que a forma como as informações estavam organizadas no aplicativo ajudaram a manter a sua atenção no aplicativo (Q18). Outro resultado positivo foi observado quando questionados sobre a relevância do conteúdo educacional, os resultados demonstraram que $70,4 \%$ dos participantes concordaram que estava claro que o conteúdo educacional do aplicativo tinha relação com o que conheciam (Q19) e 66,7\% indicaram que completar com sucesso as atividades propostas com o aplicativo era importante (Q20).

Na dimensão de confiança, mais de 55,5\% indicou estar confiante de que aprendeu o que deveria após utilizar o aplicativo (Q21), porém, somente $51 \%$ estava confiante de que havia entendido o conteúdo educacional mais complexo e $22,2 \%$ não estava confiante V. $17 \mathrm{~N}^{\circ}$ 3, dezembro, 2019 RENOTE DOI: 
(Q22), resultado que indica que em alguns casos, as simulações não contribuíram para o processo de ensino e aprendizagem a ponto de facilitar o entendimento dos conteúdos mais complexos. A respeito da dimensão de satisfação, mais da metade dos participantes indicou que completar as atividades com o aplicativo gerou um sentimento satisfatório de realização (Q23), porém, observou-se que apenas 48,1\% gostaram do conteúdo educacional a ponto de querer saber mais sobre o assunto (Q24). Entretanto, de modo geral foi possível observar que $66,7 \%$ realmente gostaram de estudar com o aplicativo de RA (Q25), aspecto que indica a capacidade de explorar possibilidades dessa tecnologia na educação, a fim de atender aos anseios dos usuários, sendo preciso apenas buscar formas de motivá-los a querer saber mais sobre o conteúdo educacional.

No âmbito da motivação, foi possível perceber que o aplicativo tem informações e simulações que mantém a atenção do usuário de maneira parcial, com conteúdos educacionais relevantes e que passam confiança para os usuários realizarem os experimentos em nível básico. Se torna importante ressaltar que para conteúdos mais complexos, os usuários sentem maior insegurança para realizar as atividades, mas que gostaram dos assuntos apresentados e resultam em deixá-los motivados a buscar novos conhecimentos.

\section{CONSIDERAÇÕES FINAIS}

O desenvolvimento do presente estudo possibilitou uma análise de como uma atividade experimental utilizando RA permitiu aos alunos aprenderem conceitos de radiação e espectroscopia, através do referencial teórico da teoria da aprendizagem significativa, formulada por Ausubel. Para isso, utilizou-se de celulares contendo o aplicativo avatARUFRGS instalados permitindo uma interação ativa dos estudantes em relação a experimentação, uma vez que eles manejavam o aplicativo de RA e discutiam sobre a atividade. De acordo com Lopes e Ribeiro (2018), as ferramentas tecnológicas auxiliam na aprendizagem do aluno, tornando-os mais ativos e autônomos, diferente da sala de aula tradicional, puramente expositiva. Desta forma, a utilização potencial dessa ferramenta possibilita ao aluno pensar, raciocinar, decifrar e aprender por si próprio e, com isso, motivando-os a descobrir novos conhecimentos.

No decorrer da atividade, eles interagiram mais abertamente com o experimento, com os colegas presentes e com os professores. Essa interação permitiu analisar as falas dos alunos, para compreender os conceitos externalizados pelos estudantes. Percebemos, pelas falas, que grande parte dos alunos possuíam conhecimentos prévios acerca de radiação. Com isso, a introdução do conceito de espectroscopia foi facilitada. Os aprendizes, ao observarem a atividade, relatavam as diferentes cores do espectro de cada elemento, entendendo que cada átomo emitia um espectro diferente. Isso evidencia uma aprendizagem por descoberta. Ainda se notou que alguns alunos relacionaram o experimento com conceitos ligados à área de estudo deles, indagando o professor acerca da análise dos solos utilizando espectroscopia. Essa ligação entre o cotidiano da profissão e a atividade experimental é um indicativo de que houve uma aprendizagem significativa.

A interação entre o aluno, o professor e o experimento pode não ter sido atrativa para os alunos que responderam os questionamentos de forma errônea e consequentemente, ocorreu o não protagonismo desses estudantes no processo de aprendizagem, do qual esse conceito é fundamental para construção do conhecimento do sujeito inserido no âmbito escolar (Gaspar e Monteiro, 2005).

Em relação ao fator motivação na abordagem RA Móvel, podemos perceber que grande parte dos alunos se sentiram instigados a aprender mais sobre o experimento e se sentiam seguros quanto aos conceitos aprendidos com a atividade. Isso mostra que as TIC 
poderiam ter mais espaço nas aulas ministradas na educação de nível superior, mostrando ao aluno que o processo de construção do conhecimento pode ser algo atrativo e expressivo no contexto em que ele está inserido.

A atividade utilizando RA acerca de espectro atômico e radiação permitiu aos alunos entenderem como o fenômeno físico interfere em seu cotidiano, além de instigar o aluno a aprender e refletir sobre os novos conhecimentos apresentados, respondendo a problemática sobre contribuições da RA para o ensino de física. Vale ressaltar que o importante não é utilizar o recurso do qual o aluno é meramente um receptor e sim o uso para promover interação entre os sujeitos do processo de ensino e aprendizagem e então contribuir na construção do conhecimento.

\footnotetext{
${ }^{1}$ É possível explorar as diversas simulações que tem potencial no ensino de física, e principalmente a espectrometria dos gases, que é o objeto de estudo do presente trabalho, pela homepage do projeto AVATAR: http://www.ufrgs.br/avatar/realidade-aumentada.
}

\section{REFERÊNCIAS}

AlveS, M. P.; MORGAdO, J. C.; LEMOS, A. R.; RODRIGUES, S. C.; SÁ, S. O. Práticas inovadoras no ensino superior. Universidade do Porto. Centro de investigação e intervenção educativas, Porto, 2012.

AUSUBEL, D.P. A aprendizagem significativa: A teoria de David Ausubel. São Paulo; Moraes 1982.

BARBOSA, C. M. A. M. A aprendizagem mediada por TIC: Interação e cognição em perspectiva. Associação Brasileira de Ensino a Distância, p. 83-100, 2012.

BARBOSA, P. P. A.; LIMA, W. V. C.; LOBO, C. O. L; LUDKE, E. Espectroscopia: Uma atividade experimental para o ensino a área de ciências da natureza. Vivências:

Revista eletrônica de extensão da URI, v.15, n.28, p. 100-110, 2019.

CHAVES, E. O. C. A tecnologia e a educação. Encyclopaedia of Philosophy of Education, Campinas, 1999.

GASPAR, A; MONTEIRO, I. C. C. Atividades experimentais de demonstração em sala de aula: Uma análise segundo o referencial da teoria de Vygotsky. In: Investigações em Ensino de Ciências. v. 10, n. 2, p. 227-254, 2005.

GIL, A. C. Como elaborar projetos e pesquisa. 4 ed. São Paulo: Atlas, 2002.

HERPICH, F. et al. Modelo de Avaliação de Abordagens Educacionais em Realidade Aumentada Móvel. RENOTE, v. 17 n. 1, julho, 2019, 355-364.

LOPES, L. M. M.; RIBEIRO, V. S. O estudante como protagonista da aprendizagem em ambientes inovadores de ensino. In: Congresso internacional de educação e tecnologias, CIET:EnPED, 2018. Disponível em: http://cietenped.ufscar. br/sumissao/index.php/2018/article/view/286. Acesso em 25 jun. 2019.

MOREIRA, M. A. Subsídios teóricos para o professor pesquisador em ensino de ciências. Porto Alegre, 2009. Disponível em: http://www.if.ufrgs. br/ moreira/subsidio6.pdf. Acesso em 25 jun. 2019.

MOREIRA, M. A. O que é afinal aprendizagem significativa?. Revista cultural La Laguna Espanha, 2012. Disponível em: http://moreira.if.ufrgs.br/oqueeafinal.pdf. Acesso em 22 jun. 2019.

SERIO, A. D.; Iaez, M; KLOOS, C. D. Impact of an augmented reality system on students motivation for a visual art course. Computers and education, v.68, p.586-596, out. 2013. TRINDADE, R. Os benefícios da utilização das TIC no Ensino Superior: A perspectiva docente E-Learning. Educar em revista, Curitiba, p. 211-233 n. 4/2014. 